\title{
RANCANGAN SISTEM PEMBAYARAN UANG KURSUS BERBASIS ANDROID
}

\author{
Arimaya Setyorini \\ Program Studi Informatika, Fakultas Teknik dan Ilmu Komputer, Universitas Indraprasta PGRI \\ Jalan Raya Tengah No 80, Kelurahan Gedong, Pasar Rebo, Jakarta Timur \\ arimayasetyorini@gmail.com
}

\begin{abstract}
Abstrak
Smartphone merupakan telepon genggam atau telepon seluler pintar yang dilengkapi dengan fitur mutakhir dan berkemampuan tinggi layaknya sebuah komputer. Selain dilihat dari fungsinya, smartphone juga menjadi populer lantaran praktis. Penerapan teknologi smartphone berbasis aplikasi android, cenderung diminati di dunia bisnis dengan berbagai jenis bidang usaha, seperti halnya kegiatan usaha tempat kursus. Rancangan Sistem Pembayaran Uang Kursus Berbasis Android adalah aplikasi yang peneliti rancang untuk membantu mengatasi permasalahan yang ada dalam pengelolaan pembayaran uang kursus yang masih manual sehingga mengalami kesulitan dalam memantau data pembayaran, tunggakan, bahkan dapat terjadi kesalahan dan kehilangan data. Penelitian ini menggunakan metode Software Development Life Cycle (SDLC) dengan model pendekatan Prototype. Aplikasi berbasis android ini memanfaatkan layanan clientserver, device android sebagai client dan MySQL sebagai database di server. Terdapat berbagai menu diantaranya menu login, menu utama dimana dalam menu ini terdapat sub menu kelola data murid, kelola pembayaran murid, menu laporan data murid dan laporan pembayaran murid. Aplikasi ini dirancang sesuai dengan kebutuhan dalam kegiatan pengelolaan pembayaran uang kursus sehingga pengelolaan data murid, proses pencatatan pembayaran uang kursus dan pelaporan kepada orangtua murid menjadi lebih mudah dan praktis. Data pembayaran uang kursus tersedia dalam satu genggaman, sehingga data selalu tersedia kapanpun.
\end{abstract}

Kata Kunci: Uang Kursus, SDLC, Prototype, Aplikasi Android Client-Server

\begin{abstract}
A smartphone is a mobile phone or smartphone equipped with state-of-the-art and highly capable features like a computer. In addition to its functionality, smartphones also become popular because they are practical. The application of smartphone technology based on android applications, tends to be in demand in the business world with various types of business areas, as well as business activities where the course. The Android-based Course Money Payment System design is an app that researchers designed to help solve problems in managing manual course money payments that have difficulty monitoring payment data, arrears, and even data loss. This research uses the Software Development Life Cycle (SDLC) method with prototype approach model. This android-based application utilizes client-server service, android device as client and MySQL as database on server. There are various menus including login menu, main menu where in this menu there is a sub menu manage student data, manage student payments, menu student data report and student payment report. This application is designed according to the needs in the course money payment management activities so that the management of student data, the process of recording the payment of course money and reporting to parents of students becomes easier and practical. Course money payment data is available in one hand, so data is always available at any time.
\end{abstract}

Keywords: Tuition fees, SDLC, Prototype, Android Client-Server Application

\section{PENDAHULUAN}

Smartphone merupakan telepon genggam atau telepon seluler pintar yang dilengkapi dengan fitur mutakhir dan berkemampuan tinggi layaknya sebuah komputer. Selain dilihat dari fungsinya, smartphone juga menjadi populer lantaran praktis, mudah dibawa kemana saja. Perkembangan smartphone yang kian canggih menyebabkan perubahan yang signifikan terhadap sebagian besar kebiasaan para penggunanya. Bukan hanya sebagai alat komunikasi, namun smartphone kini dianggap telah mampu menyediakan berbagai macam kemudahan dalam aktivitas sehari-hari, baik itu untuk keperluan pendidikan, pekerjaan, maupun sekadar hiburan. Tak jarang, banyak orang yang bergantung pada smartphone. 
Salah satu sistem operasi pada smartphone yang banyak diminati pengembang yaitu android karena bersifat opensource yaitu menyediakan platform yang terbuka bagi siapa saja untuk membuat aplikasi sendiri. Menurut (Sutabri, 2012) suatu sistem dapat diartikan sebagai suatu kumpulan atau himpunan dari unsur, komponen, atau variabel yang terorganisir, saling berinteraksi, saling tergantung satu sama lain dan terpadu. Menurut (Safaat, 2012) Android merupakan sistem operasi untuk telepon seluler yang berbasis Linux. Android menyediakan platform terbuka bagi para pengembang untuk menciptakan aplikasi mereka. Maka dari itu peneliti mencoba untuk menerapkan teknologi smartphone berbasis aplikasi android yang cenderung banyak diminati dalam pembayaran uang kursus di Filarmonica Course, tempat kursus alat musik piano yang berlokasi di Jalan Raya Bogor KM. 45 No. 1 RT 01 RW 11, Pabuaran Cibinong Bogor. Minimnya karyawan menjadikan Bapak Bagus Nurdianto selaku pemilik tempat kursus tersebut, harus mengelola sendiri usahanya. Setiap bulannya, Pak Bagus mencatat pembayaran atas uang kursus dari para murid kedalam sebuah buku. Proses pencatatan atas pembayaran yang masih manual ini menimbulkan kesulitan dalam melihat data pembayaran uang kursus. Bahkan sempat terjadi kerusakan dan kehilangan buku pembayaran. Di samping itu, Pak Bagus harus merekap manual untuk mengetahui murid yang masih ada tunggakan. Apabila ada orangtua murid yang menanyakan status pembayaran uang kursus anaknya lewat telepon atau pesan singkat, Pak Bagus tidak bisa langsung memberikan informasi ketika tidak berada di lokasi karena buku pencatatan pembayaran tidak dibuat rangkap, hanya disimpan di tempat kursus saja.

Peneliti membuat solusi dengan pemanfaatan teknologi berupa aplikasi yang memudahkan pencatatan pembayaran uang kursus yang semula manual menjadi aplikasi berbasis android untuk admin yang mampu menambahkan, menghapus, mengubah, mencari data, sehingga mudah dan tidak memakan waktu yang lama karena langsung tersimpan di database yang dapat diakses kapanpun dan dimanapun.

\section{PENELITIAN RELEVAN}

Penelitian relevan merupakan penelitian terdahulu atau sebelumnya yang relevan dengan konsep penelitian sehingga menjadi acuan atau dasar mengembangkan suatu hasil penelitian sebelumnya. Hasil penelitian yang terdahulu dapat dipakai sebagai acuan untuk melakukan penelitian selanjutnya. Meskipun ada perbedaan pada objek atau variabel yang diteliti. Penelitian yang peneliti jadikan penelitian relevan adalah penelitian oleh (Hendrik Ika Dita Widia, 2017). Penelitian tersebut bertujuan untuk Untuk membuat Sistem Informasi Pembayaran SPP yang dapat membantu proses pengolahan data administrasi pembayaran di SMK Pawyatan Daha 3 Kediri. Penelitian relevan selanjutnya adalah penelitian oleh (Lauren \& Murtiwiyati 2013)dengan judul "Rancang Bangun Aplikasi Pembelajaran Budaya Indonesia Untuk Anak Sekolah Dasar Berbasis Android".Penelitian ini bertujuan untuk merancang aplikasi pembelajaran budaya yang dapat menampilkan informasi tentang budaya Indonesia.

\section{METODE PENELITIAN}

Metode penelitian yang digunakan dalam penelitian ini adalah Metode Software Development Life Cycle (SDLC) dengan tahapannya yaitu penginisialisasian, pengembangan konsep sistem, perencanaan, analisa kebutuhan, desain, pengembangan, pengujian, implementasi, serta pemeliharaan sistem secara bekala dan menyesuaikan dalam pengembangan bisnis. Sementara itu dalam pengembangan aplikasi yang dibuat, menggunakan model pendekatan prototype, model ini memunculkan komunikasi dan peran aktif dari pengguna dan pengembang aplikasi sehingga menghasilkan aplikasi yang sesuai dengan yang diharapkan pengguna. Adapun metode pengumpulan data yang dilakukan oleh peneliti dalam mendapatkan data-data serta informasi untuk mendukung penyempurnaan hasil dari penelitian ini yaitu menggunakan metode lapangan yang mencakup observasi dan wawancara, juga metode kepustakaan sebagai penyokong dan penguat secara teoritis.

\section{HASIL DAN PEMBAHASAN}

Desain arsitektur aplikasi dibuat dengan menggunakan alat/tool diagram Unified Modeling language (UML). Dalam merancang aplikasi pembayaran uang kursus berbasis android 
menggunakan activity diagram untuk menggambarkan proses-proses sehingga mudah dipahami dan mudah dilihat berdasarkan urutan langkah dari suatu proses ke proses lainnya dan menyederhanakan rangkaian proses atau prosedur untuk memudahkan pemahaman pengguna terhadap informasi tersebut. Di samping itu, fungsi-fungsi dalam aplikasi juga dapat terlihat pada use case diagram.

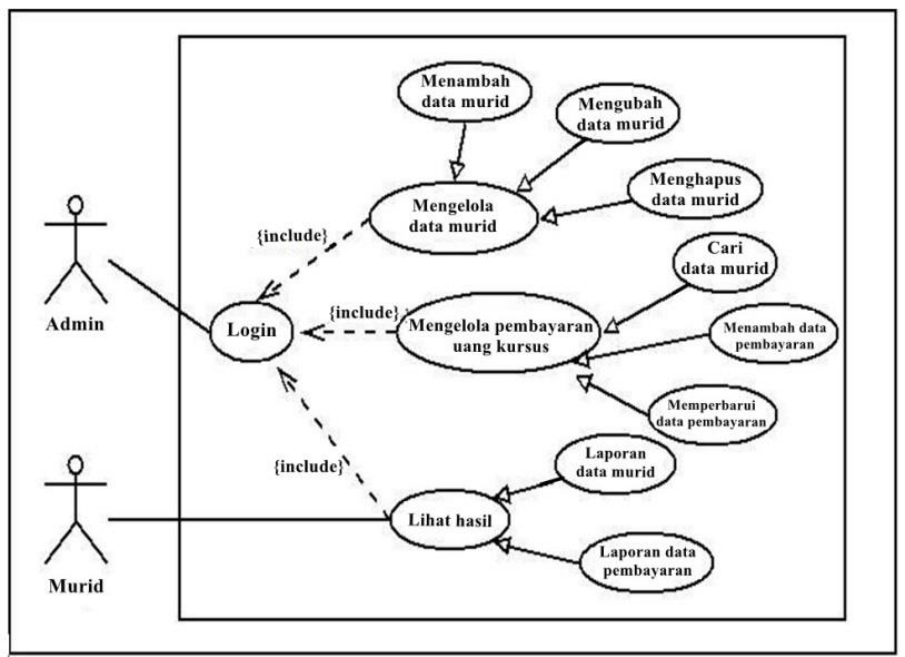

Gambar 1. Use Case Diagram

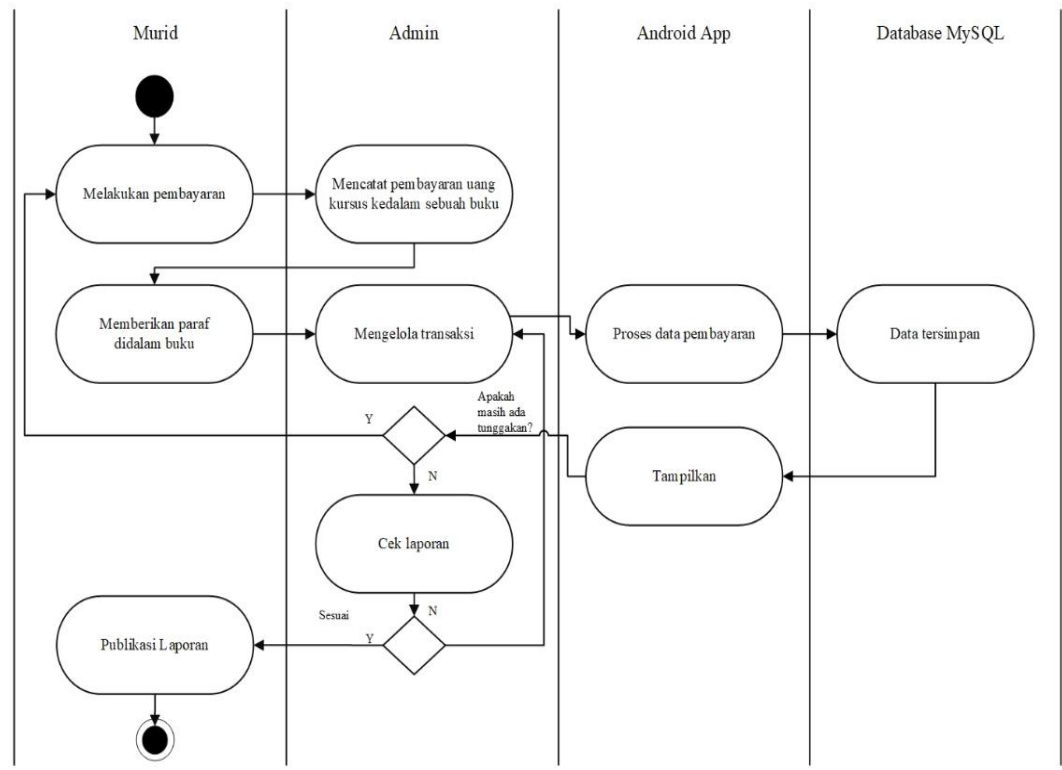

Gambar 2. Activity Diagram System 


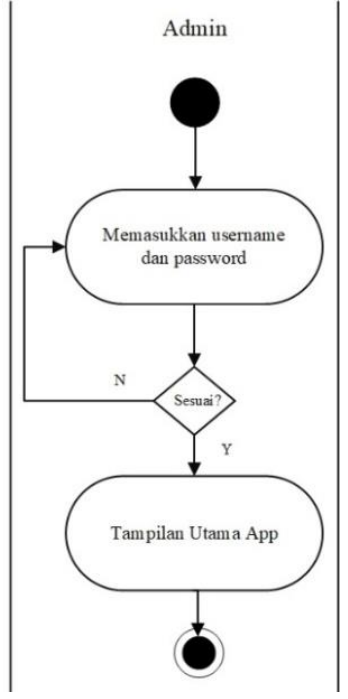

Gambar 3. Activity Diagram Login

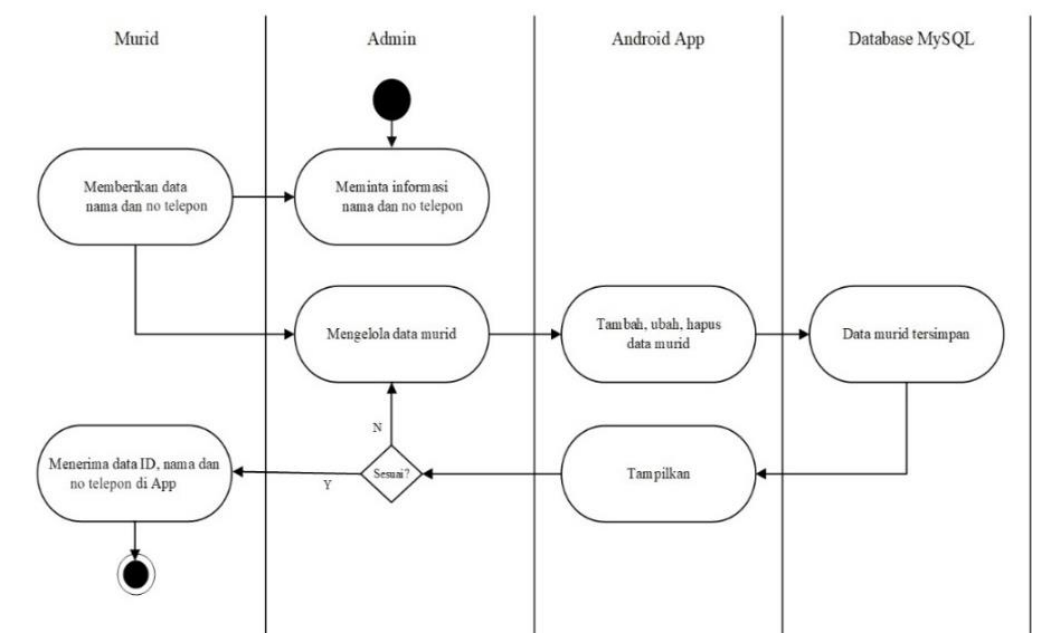

Gambar 4. Activity Diagram Pengelolaan Data Murid

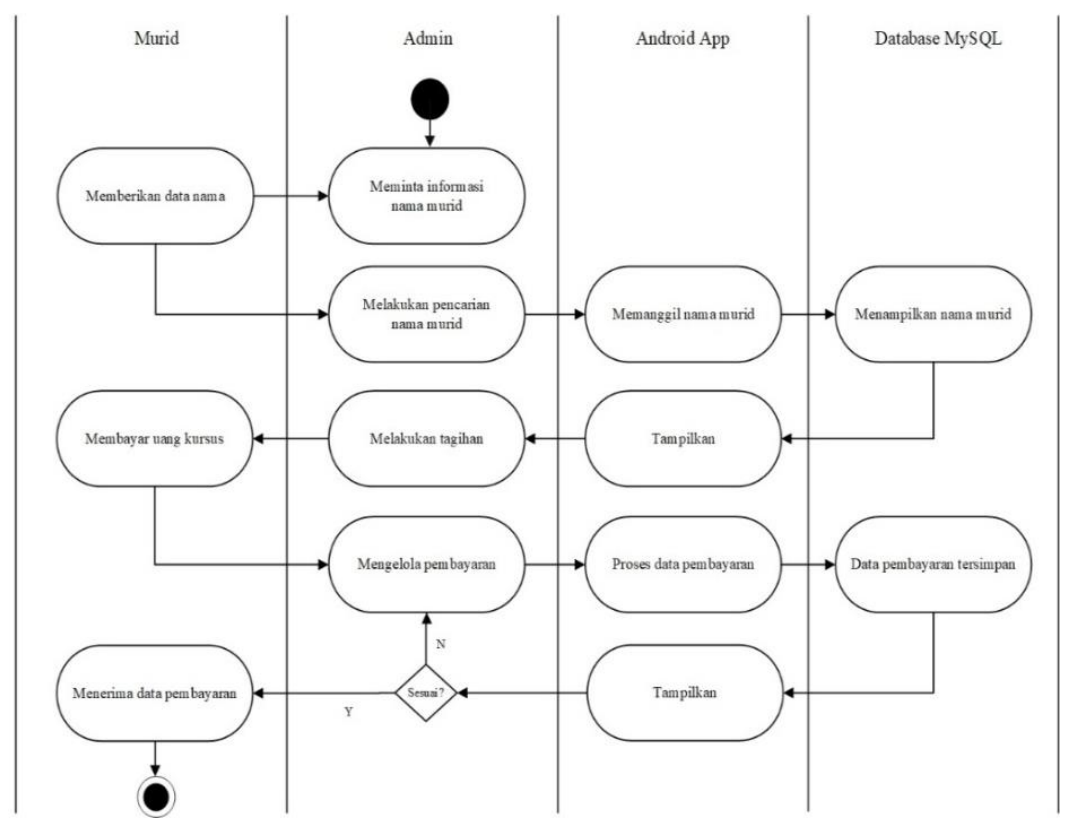

Gambar 5. Activity Diagram Pengelolaan Transaksi Pembayaran 


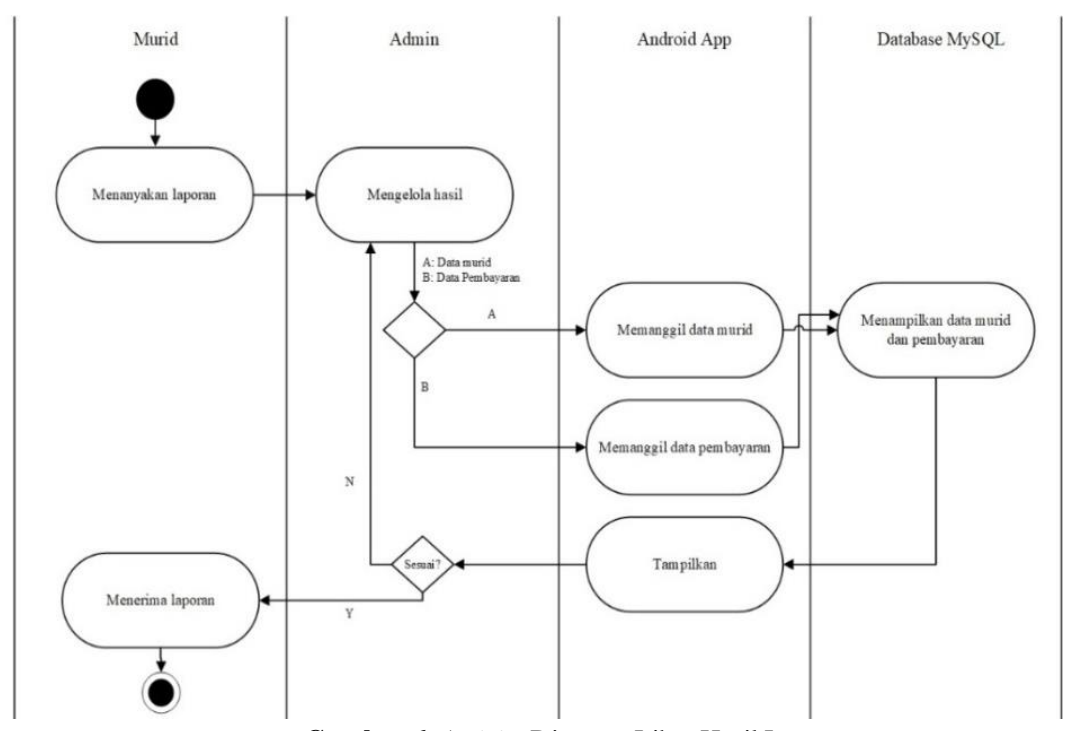

Gambar 6. Activity Diagram Lihat Hasil Laporan

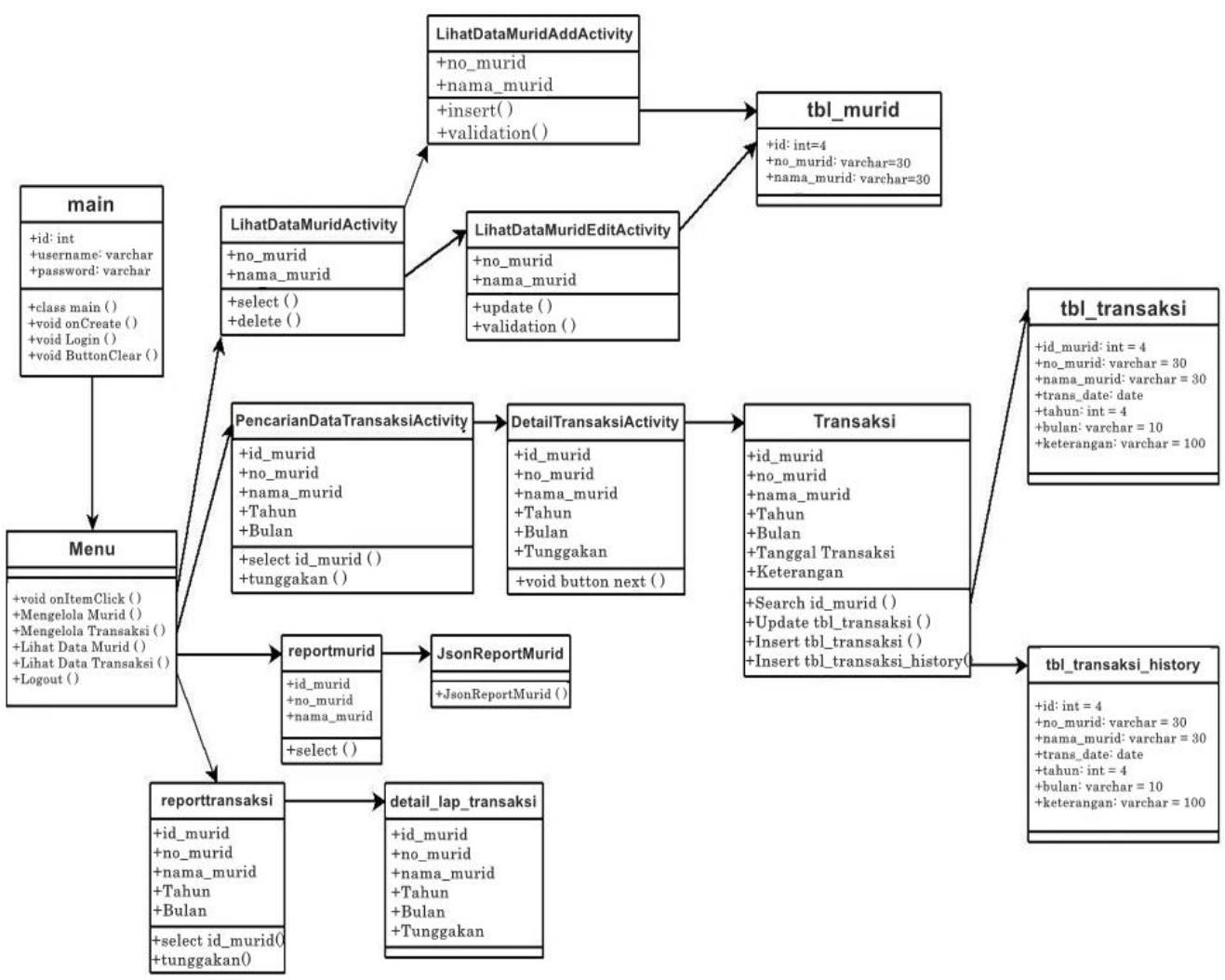

Gambar 7. Class Diagram

Berikut ini adalah beberapa rancangan antarmuka aplikasi pembayaran uang kursus berbasis Android. Dibuat dengan mengutamakan kesederhanaan tanpa mengesampingkan User Experience $(U X)$ sehingga mudah dipahami, disusun secara teratur dan sistematis, antara lain: 


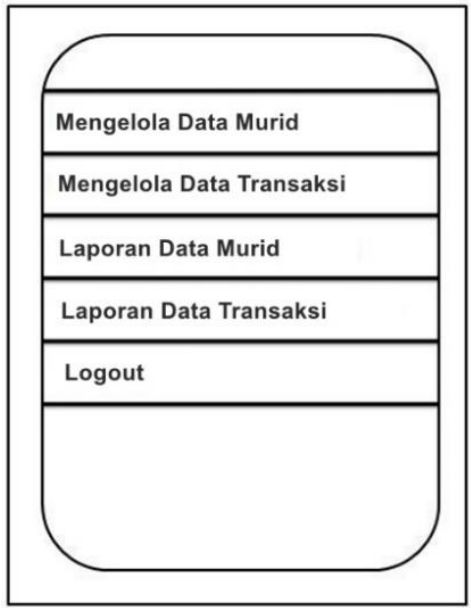

Gambar 8. Rancangan Menu Utama

Pada rancangan menu utama terdapat beberapa menu yaitu menu mengelola murid, mengelola data transaksi, laporan data murid, laporan data transaksi dan logout.

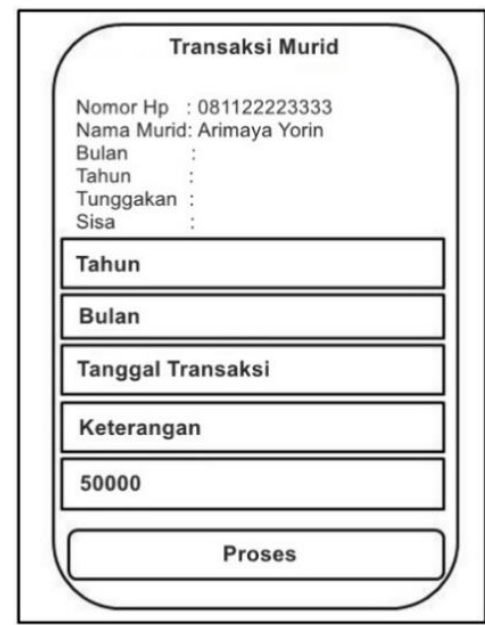

Gambar 9. Rancangan Transaksi Murid

Pada rancangan menu transaksi pembayaran terdiri dari beberapa field seperti No. HP, Nama Murid, Bulan, Tahun, Tunggakan, Sisa, Tanggal Transaksi dan Keterangan yang berfungsi untuk menginput data Transaksi Murid. Terdapat juga Menu Proses untuk memproses transaksi.

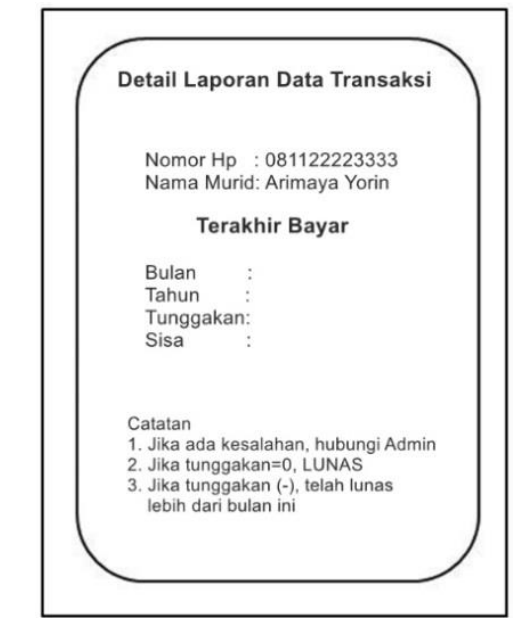

Gambar 10. Rancangan Laporan Data Transaksi 
Pada rancangan menu laporan transaksi merupakan rincian laporan data transaksi pembayaran dari setiap murid maupun seluruh murid sesuai dengan selection yang dilakukan.

Berikut ini adalah beberapa user interface yang peneliti implementasikan.

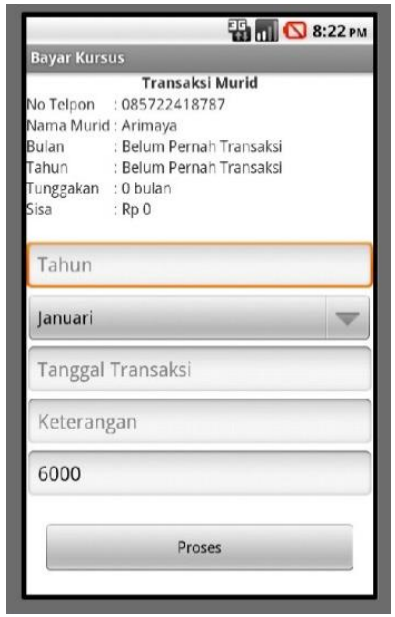

Gambar 11. Tanpilan Layar Menu Transaksi Pembayaran

Pada tampilan menu transaksi pembayaran diadmin dapat melakukan pencarian terhadap data murid dalam satu interface, sehingga dapat langsung melanjutkan untuk penginputan transaksi pembayarannya. Tanggal transaksi memiliki nilai default today dan default nominal pembayaran uang kursus sesuai custom yang telah pengguna setting di awal, sehingga apabila murid melakukan pembayaran lebih akan terkalkulasi otomatis dan pencatatan masuk ke bulan berikutnya (bayar lebih).

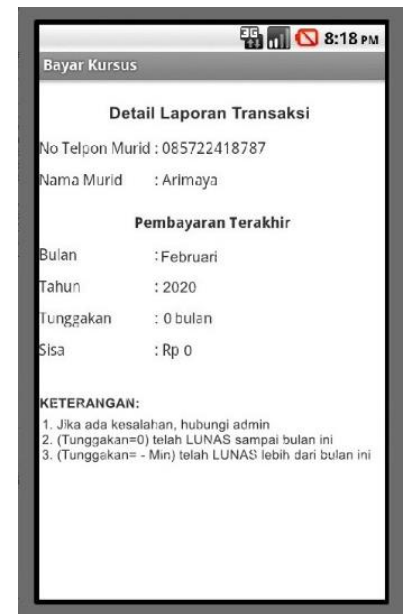

Gambar 12. Implementasi Layar Menu Laporan Data Transaksi

Pada menu laporan transaksi, dapat terpantau rincian data transaksi pembayaran dari setiap murid maupun seluruh murid sesuai dengan selection yang dilakukan. Setiap orangtua murid dapat langsung melihat laporan tanpa perlu menanyakan ke admin seperti sebelumnya. Laporan tersaji hanya sesuai dengan username saat login, sehingga hanya user bersangkutan yang dapat melihat laporan atas dirinya sendiri, kecuali admin tempat kursus yang memiliki hak akses penuh.

Uji coba aplikasi dan program dalam perancangan dan pembuatan aplikasi pembayaran uang kursus ini dilakukan dengan pengetesan fungsi dan logika yang telah ditulis pada masing-masing program atau package, apakah masih terdapat kesalahan atau tidak. Dengan menjalankan program, dapat dideteksi kesalahan yang ada dan fungsi-fungsi yang tidak sesuai. Uji coba dilakukan dengan dua metode, yaitu Pengujian Black Box Testing berfokus pada fungsi sistem, tentang kesalahan pada antarmuka, fungsi, basis data atau kesalahan kinerja sistem dan White Box Testing dilakukan 
terakhir sebelum sistem diimplementasikan. Strategi ini digunakan untuk melihat mekanisme internal dari suatu produk perangkat lunak, khususnya untuk mengamati struktur dan logika kodekode program yang ditulis. Strategi ini dapat dilakukan dengan cara meninjau langsung kode program (source code) yang ditulis dalam membangun perangkat lunak.

\section{SIMPULAN}

Dengan adanya aplikasi ini, pengelolaan data pembayaran uang kursus menjadi lebih rapi, mudah dalam penggunaannya (user friendly), serta data tersimpan dalam database yang dapat diakses kapanpun dan dimanapun. Memudahkan proses monitoring atas data pembayaran murid. Meminimalkan kekeliruan dan kerusakan atau kehilangan data. Penggunaan kertas berkurang dan tidak membutuhkan tempat penyimpanan data yang besar. Data menjadi transparan serta mudah dicapture untuk memberikan informasi tunggakan pembayaran kepada orangtua murid, sehingga informasi lebih cepat didapat. Diharapkan aplikasi yang telah dirancang ini agar dijadikan bahan untuk pengembangan sistem lebih lanjut sehingga menjadikan aplikasi lebih sempurna dan dapat menyesuaikan kebutuhan, serta tampilan antar muka aplikasi dapat dibuat lebih menarik untuk kedepannya agar tidak terkesan kaku.

\section{DAFTAR PUSTAKA}

A.S., M. S. (2011). Modul Pembelajaran: Rekayasa Perangkat Lunak (Terstruktur Dan Berorientasi Objek). Bandung: Modula.

Hariyanto, B. (2010). Esensi-Esensi Bahasa Pemrograman Java (Edisi Ketiga). Bandung: Informatika.

Hendrik Ika Dita Widia. (2017). Sistem Informasi Pembayaran Spp Pada Smk Pawyatan Daha 3 Kediri. Simki-Techsain, 01(05), 1-7

Kustiyahningsih, Y. (2011). Pemrograman Basis Data Berbasis Web Menggunakan Php \& Mysql. Yogyakarta: Graha Ilmu

Lauren, G. \& M. (2013). Rancang Bangun Aplikasi Pembelajaran Budaya Indonesia Untuk Anak Sekolah Dasar Berbasis Android. Jurnal Ilmiah Komputasi, 12(2)

Mustakini, J. H. (2014). Analisa dan Desain Sistem Informasi. Yogyakarta: Andi Offset.

Pressman, R. S. (2012). Rekayasa Perangkat Lunak-Buku Satu Pendekatan Praktisi (Edisi 7). Yogyakarta: Andi Offset.

Rizky, S. (2011). Konsep Dasar Rekayasa Perangkat Lunak. Jakarta: PT. Prestasi Pustakarya.

Safaat, N. (2012). Pemrograman Aplikasi Mobile Smartphone Dan Tablet PC Berbasis Android. Bandung: Informatika. Sutabri, T. (2012). Analisis Sistem Informasi. Yogyakarta: Andi Offset.

Widia, H. I. (2017). Sistem Informasi Pembayaran SPP pada SMK Pawyatan Daha 3 Kediri. Jurnal Ilmiah Simki-

Techsain vol. 01 no. 05, 3-8. 